
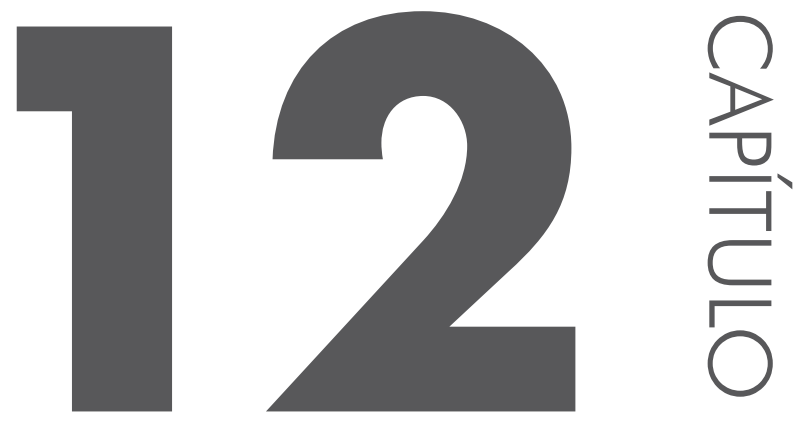

\title{
RELAC̣ÕES DE GÊNERO E FORMAS DE TRATAMENTO EM UMA COMUNIDADE RELIGIOSA
}

\author{
Cristiane Conceição de Santana \\ Thaís Regina Conceição de Andrade \\ Raquel Meister Ko. Freitag
}

\section{INTRODUC̣ÃO}

$\mathrm{Na}$ perspectiva de terceira onda de estudos sociolinguísticos, Eckert (2012) propõe a mudança do foco dos estudos da correlação entre estrutura linguística e estrutura social - predominante na Sociolinguística Varia- 
cionista de base laboviana - para as práticas e seus valores em uma dada comunidade, incorporando, dessa forma, a dinamicidade da estrutura com os condicionamentos sociais impostos e as relações de poder estabelecidas atuando sobre dada comunidade. A proposta de mudança do foco requer também uma mudança no aparato metodológico, com o estudo de comunidades de práticas.

Para Eckert e McConnell-Ginet (2010 [1992]), uma comunidade de prática se caracteriza por ser constituída por pessoas que se reúnem em prol de um objetivo comum, em torno do aprendizado e, principalmente, da sua aplicação prática, podendo ela ser constituída por pessoas trabalhando juntas em uma empresa, a família nuclear, grupos religiosos etc. Essas comunidades podem ser grandes ou pequenas, intensas ou difusas; podem sobreviver a várias mudanças de membros e ainda podem estar articuladas a outras comunidades. Assim, as pessoas participam de múltiplas comunidades de prática, e a identidade individual é baseada na multiplicidade dessa participação. Dessa forma, no lugar de conceber o indivíduo como uma entidade à parte, pairando sobre o espaço social, ou como um membro de um grupo específico, ao invés disso, é preciso enfocar nas comunidades de prática, pois esses espaços sociais nos possibilitam ver o indivíduo como agente articulador de uma variedade de formas de participação em múltiplas comunidades de prática.

A observação das formas de tratamento em comunidades de práticas permite um olhar mais acurado para os valores associados ao fator social sexo/gênero no âmbito local (o que é prestígio para certos grupos não o é para outros), viabilizando uma discussão sobre o que é marca linguística de prestígio e o que é marca linguística de estigma em microssituações.

A Sociolinguística analisa o comportamento linguístico de um ponto de vista social, envolvendo questões que influenciam na linguagem do indivíduo, além de aspectos ligados à sociedade. Nos últimos quarenta anos, diferentes estudos vêm tratando das diferenças linguísticas entre homem e mulher. Segundo Eckert \& McConnell-Ginet (2010[1992]), estudos sobre linguagem e gênero vêm sendo observados em diferentes dimensões, acarretando uma grande variedade de hipóteses acerca da interação de gênero e linguagem para os estudos sociolinguísticos. As interações que acontecem entre homem e mulher mostram que a relação de poder advinda dessas interações tem sido considerada como suporte da dominância masculina, enquanto para as mulheres, é vista como forte recurso a favor de seus projetos e interesses e contra a opressão. Para Eckert \& McConnell-Ginet (2010[1992], p. 95), 
A linguagem da mulher tem sido compreendida como refletindo o seu conservadorismo, consciência de prestígio, mobilidade ascendente, insegurança, deferência, encorajamento, expressividade emotiva, sensibilidade em relação aos outros, solidariedade. Já a linguagem dos homens é descrita como evidenciando sua dureza, falta de afeto, competitividade, independência, competência, hierarquia.

Essas afirmações se baseiam em estudos realizados em diferentes momentos e circunstâncias e com pessoas diferentes, para chegar a um consenso e não fazer abstrações. Para Eckert \& McConnell-Ginet (2010[1992]), a ideia de gênero é totalmente abstraída de outros aspectos sociais, e o sistema linguístico é abstraído da prática linguística. O ideal não é ignorar as caracterizações abstratas, mas ligar cada uma dessas abstrações à ampla gama de práticas linguísticas e sociais que possibilitam a análise das particularidades de sua realização concreta em comunidades reais.

Tendo em vista evidenciar como o uso linguístico se reflete nas relações entre homens e mulheres levando em consideração a influência das formas de tratamento, buscamos com esta pesquisa colaborar com os estudos de gênero/sexo em comunidades de práticas nos estudos sociolinguísticos.

\subsection{CONTEXTUALIZAC̣ÃO DA COMUNIDADE SOB ANÁLISE}

A comunidade "Mãe da Divina Graça” é um grupo de cunho religioso, a maioria dos membros são pessoas mais velhas; com um nível de escolarização bastante diversificado, indo do fundamental menor ao ensino superior, e também pessoas não escolarizadas, todos os membros, desta comunidade, são residentes da zona rural, no povoado Açuzinho ${ }^{1}$ em Lagarto/SE. O grupo Mãe da Divina Graça é formado por adultos e idosos da faixa etária de 22 a 83 anos; para melhor sistematização, apresentamos no quadro 1 uma relação com os nomes e idades de cada um deles em ordem crescente.

1 O Açuzinho é um povoado do município de Lagarto que preserva tradições religiosas desde sua formação, muitos movimentos são organizados na capela da comunidade e o principal deles é o movimento da Legião de Maria, Organização da igreja católica fundada na Irlanda por Frank Dulff, no ano de 1921. (FREITAG, SANTANA; ANDRADE, 2014) 
Quadro 1: Relação de nomes e faixa etária dos integrantes da comunidade de prática Mãe da divina Graça.

\begin{tabular}{|c|c|c|c|c|}
\hline & Idade & Escolaridade & Sexo & Cargo \\
\hline Mon & 22 anos & Ensino Superior & Feminino & Membro \\
\hline RaN & 42 anos & Ensino Superior & Feminino & Secretário \\
\hline Vel & 43 anos & $8^{\text {a }}$ série E. F. & Feminino & Tesoureiro \\
\hline Ire & 46 anos & Ensino Superior & Feminino & Presidente \\
\hline Gel & 54 anos & $4^{\text {a }}$ Série & Feminino & Membro \\
\hline Mau & 60 anos & Ensino médio & Feminino & Membro \\
\hline RaR & 64 anos & Não escolarizada & Feminino & Membro \\
\hline RaA & 64 anos & $4^{a}$ série E. F. & Feminino & Vice-presidente \\
\hline Edv & 71 anos & $2^{\text {a série E. F. }}$ & Masculino & Membro \\
\hline MaL & 72 anos & Não escolarizada & Feminino & Membro \\
\hline MaM & 73 anos & Não escolarizada & Feminino & Membro \\
\hline MaP & 83 anos & Não escolarizada & Feminino & Membro \\
\hline
\end{tabular}

A comunidade é constituída por 13 membros, dos quais 12 são do sexo feminino e apenas um do sexo masculino. Esse grupo se organiza de forma hierárquica, subdividindo-se em 4 membros oficiais (presidente, vice-presidente, secretário e tesoureiro) e 9 membros ativos, como podemos ver no quadro 2 . 
Quadro 2: Distribuição dos membros quanto ao cargo e à função.

\begin{tabular}{|c|l|}
\hline Cargo/Membro & \multicolumn{1}{|c|}{ Função } \\
\hline Presidente & $\begin{array}{l}\text { Exerce o papel principal na hierarquia do grupo, é } \\
\text { quem inicia e finaliza a reunião, estabelece a ordem } \\
\text { das leituras, escolhe quem vai falar em determinado } \\
\text { momento, define onde será realizado o trabalho } \\
\text { voluntário etc. }\end{array}$ \\
\hline Vice-presidente & $\begin{array}{l}\text { Pode substituir a presidente, quando necessário, e tem } \\
\text { a função de recepcionar visitantes e/ou convidados e } \\
\text { fazer a chamada de frequência dos membros. }\end{array}$ \\
\hline Secretária & $\begin{array}{l}\text { Exerce a função de redigir e ler a ata da reunião e } \\
\text { relatar sobre o trabalho realizado durante a semana } \\
\text { anterior. }\end{array}$ \\
\hline Tesoureira & $\begin{array}{l}\text { É responsável por cuidar das finanças, coletando } \\
\text { dinheiro para despesas como decoração da igreja, } \\
\text { fotocópias, impressões, viagens do grupo para } \\
\text { reuniões com outros conselhos, registrando os valores } \\
\text { coletados e prestando contas de como foram gastos. }\end{array}$ \\
\hline Membros ativos & $\begin{array}{l}\text { Recebem todas as instruções de quem os lidera e } \\
\text { podem interagir ou debater os assunto no momento } \\
\text { em que acharem oportuno. }\end{array}$ \\
\hline
\end{tabular}

Essa organização de líderes e liderados funciona de modo que a liderança permite ao líder o poder de propor inovações, até mesmo linguísticas, já que o grupo de liderados os legitima e o segue, aderindo aos comportamentos de quem os lidera, ou seja, a fala do líder inspira os outros participantes do grupo a falarem de forma semelhante e/ou terem um comportamento similar. Essa é uma característica típica em comunidades de práticas, pois todo agrupamento de pessoas que se reúnem em um propósito em comum necessita que alguém sempre esteja à frente para tomar decisões e posicionamentos para que a comunidade obtenha progresso diante dos objetivos almejados.

A comunidade de prática Mãe da Divina Graça tem como objetivo capacitar os seus membros, conforme o Manual da Legião de Maria, com o intuito de trabalharem voluntariamente a serviço da comunidade local e da igreja. Os membros deste grupo se reúnem duas vezes por semana, no primeiro encontro, que acontece às segundas-feiras das $19 \mathrm{~h}$ às $20 \mathrm{~h} 30$, a reunião é bem sistemática, pré-definida com orações e discussões sobre textos religiosos. O principal objetivo do primeiro encontro semanal é a marcação de trabalhos voluntários que serão realizados durante a semana. 
Já no segundo encontro, os membros se reúnem para realizar os trabalhos já estabelecidos no primeiro; geralmente os trabalhos são visita a hospitais, a asilos e a domicílios, a limpeza da igreja etc.

$\mathrm{Na}$ sua estrutura interna, o grupo Mãe da Divina Graça se organiza de forma sistemática, a reunião é iniciada com as orações e o terço, na sequência a presidente do grupo faz a leitura espiritual, posteriormente a secretária faz a leitura da ata e logo em seguida é feita acolhida dos visitantes e dos membros. Depois é realizada a chamada de todas as pessoas do grupo, em seguida, é feito o relatório oral de cada membro, dizendo como foi realizado o trabalho da semana anterior: caso tenha sido feito, relatar como foi, e caso não, justificar o porquê.

Depois de feito o relatório, reza-se a Catena, que é o hino da Virgem Maria; em seguida, é feita a alocução, explicação da leitura espiritual, feita no início da reunião (esse rito pode ser feito por qualquer membro do grupo nomeado pela presidente); posteriormente é feita a coleta de uma contribuição. Logo em seguida, um membro pré-definido pela presidente faz o estudo do manual, que é uma breve leitura, e abre-se um espaço para que todos possam discutir o que entenderam acerca dessa leitura. Em seguida a tesoureira faz a leitura do relatório do caixa da tesouraria, expondo para o grupo o quanto foi coletado na semana anterior, o que foi feito com o dinheiro, quanto ainda há em caixa; logo após, é feita a distribuição dos trabalhos voluntários, como levar eucaristia para os doentes, visitar asilos, hospitais, penitenciárias, famílias enlutadas, etc. Depois são discutidos assuntos diversos a respeito de eventos religiosos da comunidade e da paróquia e, no encerramento do encontro, as orações finais.

Como podemos ver, os encontros seguem um ritual, são padronizados e, por isso, requerem um uso mais formal da língua. Evidências da formalidade foram encontradas na distribuição de variáveis sociolinguísticas marcadas (FREITAG, 2014). Nosso objetivo, agora, é verificar a tensão da formalidade quanto às formas de tratamento, considerando especialmente o único membro do sexo masculino.

\subsection{ANÁLISE DAS RELAC̣ÕES DE TRATAMENTO}

A metodologia adotada nessa pesquisa foi a abordagem de base etnográfica. A etnografia aplicada aos estudos sociolinguísticos tem envolvido diferentes procedimentos e caracteriza-se pelo envolvimento do pesquisador no ambiente natural da pesquisa, exigindo uma observação e uma interpretação de entendimento dos dados coletados, fazendo com que ele tome parte de alguma atividade peculiar da comunidade. Nesse método, os 
dados coletados podem ser feitos em narrativas ou história de vida, entretanto, não se pode de maneira alguma perder o ponto chave da etnografia, que é a descrição contextualizada dos fenômenos pesquisados. Com base nisso, analisamos quais as formas de tratamento utilizadas pelos membros entre si, levando em consideração sexo/gênero.

O primeiro passo da metodologia foi identificar uma comunidade de práticas que possibilitasse estudar a questão do gênero em relação à forma de tratamento. $\mathrm{O}$ segundo passo se caracterizou pelas visitas frequentes à comunidade, e após os contatos iniciais, começamos a fazer anotações de campo, as gravações das reuniões do grupo, as observações do comportamento dos membros da comunidade, descrições e estudos detalhados sobre a história da comunidade analisada e também da região onde ela se encontra, a fim de identificar fatos que pudessem ser relevantes para análise dos dados. A etnografia da comunidade pode ser conferida em Freitag, Santana e Andrade (2014).

A constituição do corpus segue as diretrizes definidas para a amostra de comunidades de práticas do banco de dados Falares Sergipanos (FREITAG, 2013; FREITAG, MARTINS, TAVARES, 2012). Selecionamos as gravações integrais de três reuniões, com duração de uma hora e trinta minutos cada. Para extração dos dados, fizemos uma leitura minuciosa das transcrições, para que pudéssemos localizar como cada membro utiliza as formas de tratamento para se dirigir ao outro, o que não poderia ser feito por extração automática.

No quadro 1, mostramos como os informantes são classificados socialmente e sua posição na hierarquia do grupo: o membro do sexo masculino não está entre os oficiais, entretanto, exerce uma influência significativa no que diz respeito à soberania, ou seja, mesmo não sendo oficial, as suas ações no grupo sugerem que ele tem a mesma autonomia que a presidente e as outras oficiais.

No quadro 3, sistematizamos as formas de tratamento utilizadas por cada membro da comunidade de prática, observando quantas vezes as formas são proferidas e para quem, qual a relação entre os membros e em que parte da reunião cada uso acontece. O grau de parentesco e a posição hierárquica dos membros também foram considerados, além das variáveis sociais (idade, sexo e escolaridade), tanto do falante quanto do ouvinte. 
Quadro 3: Distribuição das formas de tratamento entre falante/ouvinte.

\begin{tabular}{|c|c|c|c|c|c|}
\hline Forma de tratamento & $\begin{array}{c}\text { Total de } \\
\text { vezes }\end{array}$ & $\begin{array}{l}\text { Quem } \\
\text { fala }\end{array}$ & Momento da reunião & $\begin{array}{c}\text { Grau de } \\
\text { parentesco }\end{array}$ & Para quem \\
\hline "O senhor" & 3 & Ire & Alocução & Nenhum & Edv \\
\hline "A senhora" & 1 & $\mathrm{RaN}$ & $\begin{array}{c}\text { Entre a ata e a } \\
\text { chamada }\end{array}$ & Nenhum & MaL \\
\hline "Você" & 3 & Edv & $\begin{array}{l}\text { Estudo do Ma- } \\
\text { nual }\end{array}$ & Nenhum & Ire \\
\hline "Você" & 1 & Mon & $\begin{array}{l}\text { Distribuição dos } \\
\text { trabalhos }\end{array}$ & Nenhum & Ire \\
\hline "Você" & 1 & Ire & $\begin{array}{l}\text { Distribuição dos } \\
\text { trabalhos }\end{array}$ & Nenhum & Mon \\
\hline "Você" & 1 & Eda & Assuntos diversos & Nenhum & Ire \\
\hline "Comadre" & 2 & $\mathrm{RaA}$ & $\begin{array}{l}\text { Estudo do Ma- } \\
\text { nual }\end{array}$ & Nenhum & $\mathrm{Vel}$ \\
\hline "Comadre" & 1 & Vel & $\begin{array}{l}\text { Distribuição dos } \\
\text { trabalhos }\end{array}$ & Nenhum & $\mathrm{RaA}$ \\
\hline "Compadre" & 4 & Eda & Assuntos diversos & Nora & Edv \\
\hline "Seu" & 2 & Mau & $\begin{array}{c}\text { Estudo do Ma- } \\
\text { nual }\end{array}$ & Nenhum & Edv \\
\hline "Seu" & 2 & Ire & $\begin{array}{c}\text { Relatório dos } \\
\text { trabalhos }\end{array}$ & Nenhum & Edv \\
\hline "Seu" & 1 & Vel & $\begin{array}{c}\text { Distribuição dos } \\
\text { trabalhos }\end{array}$ & Nenhum & Edv \\
\hline "Dona" & 1 & Gel & $\begin{array}{c}\text { Entre a leitura } \\
\text { espiritual e a ata }\end{array}$ & Nenhum & MaL \\
\hline "Irmã" & 1 & $\mathrm{RaN}$ & Leitura da Ata & Cunhada & Mau \\
\hline "Irmã" & 2 & Mau & Leitura da Ata & Cunhada & Ire \\
\hline "Irmã" & 1 & Vel & Chamada & Nenhum & MaL \\
\hline
\end{tabular}

"Seu" Edv, como é chamado por todos os moradores do povoado Açuzinho, tem história na constituição religiosa desta localidade: não estudou formalmente, ele diz ter sido alfabetizado a partir de leituras da bíblia e textos religiosos; foi o primeiro Ministro da Eucaristia e, por dez anos, exerceu a função de presidente do grupo da Legião de Maria cuja implantação se deu através de sua vinda para o povoado.

$\mathrm{Na}$ comunidade de prática Mãe da Divina Graça, os membros se conhecem há muito tempo, e, dadas as características da constituição do povoado, há uma forte relação de parentesco entre a maioria dos compo- 
nentes, sugerindo uma forte aproximação entre si, o que pode ser evidenciado pelo fato de, na maioria das vezes, os membros costumam se chamar pelo primeiro nome ou pelo apelido. Neste caso, o diferencial pode ser analisado a partir da faixa etária, gênero, grau de parentesco e posição hierárquica no grupo.

A seguir, apresentamos excertos transcritos das reuniões que ilustram as formas de tratamento utilizadas na comunidade, especialmente os nomes e apelidos dos membros.

RaA: Irene?

Ire: presente

RaA: Raimunda Alves? Raimunda Nonata?

RaN: presente

RaAl: Velma Maria?

Vel: presente

RaA: Edvaldo?

Edv: Presente

RaA: Maurina?

Mau: presente

RaA: Gelsira?

Gel: presente

RaA: Edvanda?

Eda: Presente

RaAs: Maria Messias?

MaM: Presente

RaA: Maria de Lourdes?

MaL: Presente

RaA: Maria Pureza?

MaP: Presente

RaA: Raimunda Rodrigues?

RaR: Presente

RaA: Monise?

Mon: Presente

No caso da chamada da lista de presença, a vice-presidente chama os membros pelo primeiro nome e alguns pelo sobrenome, por ser um processo ritual da reunião. Já em momentos menos formais, os membros costumam se comunicar de forma mais íntima pelo primeiro nome, apelido entre outras.

Ire: a nossa irmã que passamos no caso passou uma semana as- 
Relações de gênero e formas de tratamento em uma comunidade religiosar sim... e ainda estamos em comunhão com ela nós marcamos para rezar os terços lá na casa de Nuna né?

(3)

Ire: $\mathrm{O}$ mesmo lugar por um novo período de três anos... no caso pode ser... eu já fui o quê? Secretária duas vezes foi? por dois mandatos pode ser Raimundinha já foi secretária do praesidium e ela continua sendo mas ela não pode ser...

(4)

RaN: Velma vai falar com a mulher... lá... se ela pretende ir pra lá nós vamos

(5)

RaA: porque Maria além dela se ( era organizada e o plano dela é organizado também... e nós mesmo pode e não precisa me (copiar nem Edinha nem ninguém... nós somos a delegada de nós mesmo e quiser entender...

Edv: com Maria ali Maria... a gente já teve lá uma vez Maurina não tava nesse dia...

Ire: então nós vamos pra casa dela nós nunca... ( então nós vamos fazer o trabalho na casa de Dadá viu? Então nós vamos pra casa de Dadá viu gente? Eu ou Velma...

Ire: (... a gente inicia o capítulo quinze compromisso legionário... não vou fazer a ordem não eu acho que eu vou me lembrar deixe eu anotar aqui Monise e Raimundinha ( eu coloco...

Nos excertos de (2) a (8), identificamos baixo grau de formalidade entre os membros estes se comunicam e fazem referência uns aos outros pelo primeiro nome ou apelido. No excerto (1) “Nuna” é RaR, membro ativa do grupo. No excerto (3), Ire, que é a presidente do grupo se dirige a RaN, secretária, como "Raimundinha", cabe destacar que Ire e RaN são cunhadas e têm um grau de intimidade mais forte. No excerto (5), "Edinha" é Eda e quem faz referência a ela é RaA, que é vice-presidente do grupo.

Mesmo os membros estando em diferentes faixas etárias, não parece haver gradação de tratamento em função deste fator. Notamos, no entanto, uma diferença no tratamento em relação ao membro do sexo masculino. 
(9)

Ire: O trabalho foi na casa de Seu Edvaldo

(10)

RaN: Foi na casa de Seu Edvaldo

(11)

Vel: o dia e a hora só com Irene e Seu Edvaldo

Nos excertos (9), (10) e (11), três membros do grupo cujas posições hierárquicas são superiores às demais, todas membros oficiais, se referem a Edv com "Seu Edvaldo". A forma de tratamento "seu”, especialmente em comunidades mais tradicionais, é um índice de deferência e respeito, especialmente na relação entre uma pessoa mais nova para com uma mais idosa, substituindo a forma "senhor". No entanto, uma membro oficial trata uma membro ativa somente pelo nome, não utilizando o "dona", ou qualquer forma equivalente para o feminino, mesmo sendo uma forma dirigida para a mais idosa da comunidade, com 83 anos, como vemos em (12).

Ire: Tá dormindo Pureza? Alguém quer falar mais alguma coisa gente?

A forma de tratamento "seu" equivale-se a "senhor" em grau de formalidade. As interações em que Mau, Ire e Vel se dirigem a Edv são marcadas pelo uso de "seu" antes do nome como forma de respeito. Todavia, o respeito que todas as membros do grupo têm por ele não se dá apenas pela questão da faixa etária, pois no grupo também existem membros do sexo feminino na mesma faixa etária ou mais velhas que Edv e, mesmo assim, são chamadas apenas pelo nome próprio ou apelido, como ilustramos no excerto (5). O tratamento "seu" tem uma valoração acentuada nesta comunidade, relacionada para a questão do gênero do falante.

O pronome de tratamento "senhor" é usado por Ire, a presidente, para se dirigir a Edv três vezes durante a alocução, que é a parte da reunião em que se faz a explicação do texto lido no início da reunião, a leitura espiritual, momento em que só pode falar uma pessoa pré-determinada pela presidente. $\mathrm{Na}$ reunião sob análise, quem explica é Edv, que é sempre tratado por todas as membros da comunidade por "senhor" e" seu", independentemente da faixa etária, da escolaridade e da posição hierárquica no grupo. Tal evidência pode sugerir uma influência do sexo/gênero, já que só existe um membro de sexo masculino no grupo.

Entre a ata e a chamada, que são dois passos formais da reunião, RaN se refere a MaL por "senhora"; elas não têm nenhum grau de parentesco 
e estão em faixas etárias diferentes. Embora seja tradição mais forte entre os moradores da zona rural tratar as pessoas mais velhas por "senhor" ou "senhora", esta é a única vez, nas reuniões analisadas, que essa forma é dirigida a uma membro do sexo feminino no grupo.

A forma "você" no português brasileiro não é mais considerada pronome de tratamento, e sim forma de referência à segunda pessoa do singular. Por conta disso, é a forma mais recorrente para dirigir-se a todos os membros da comunidade de prática Mãe da Divina Graça. No entanto, a recorrência desta forma se dá em momentos específicos da reunião, particularmente nos momentos menos formais, como é o caso da distribuição dos trabalhos e estudo do manual, e em conversar paralelas.

Tradicionalmente, as formas "comadre" e "compadre" são decorrentes do compadrio, estabelecidas no batismo. Neste rito, o batizando ganha uma segunda família, os padrinhos, estabelecendo uma relação de parentesco não sanguíneo. Assim, os padrinhos do batizando seriam tratados pelos pais, e vice-versa, por "comadre" e "compadre". Por se tratar de uma comunidade de cunho religioso e em um povoado de relações fechadas, com fortes interações de parentesco, a recorrência das formas "comadre" e "compadre" como tratamento entre os membros do grupo durante as reuniões era esperado. No entanto, nem sempre é esse o uso dado para a forma; RaA se se dirige a Vel por duas vezes por "comadre", e Vel uma vez para $\mathrm{RaAl}$, embora não haja nenhum grau de parentesco entre estas duas componentes do grupo, imaginamos que este uso decorra de uma relação mais íntima que as membros estabelecem.

No uso de "compadre", dirigido ao único membro do sexo masculino do grupo, verifica-se uma relação de parentesco, pois Eda é nora de Edv, e trata-o pela forma "compadre". Ainda assim, este tratamento só ocorre nas partes menos formais da reunião.

O tratamento “dona”, com que Gel se dirige a MaL, entre a leitura espiritual e a ata - dois momentos altamente formais da reunião - pode ser decorrente da diferença de idade entre elas.

Por se tratar de uma comunidade de práticas de cunho religioso, as formas “irmã" e "irmão" potencialmente seriam recorrentes. No entanto, identificamos poucos contextos de uso. Particularmente, nas reuniões analisadas, o uso destas formas se dá na leitura da ata e na chamada, momentos de maior formalidade; a ata tem um modelo que deve ser seguido pela secretária RaN, que, quando se refere a outro membro do grupo, neste contexto, faz uso da forma de tratamento “irmã" diante do nome próprio. 
RaN: A alocução foi feita pela irmã Irene que explicou...

RaN: No relatório da Cúria a irmã Irene leu a agenda do mês... falou da adoração ao santíssimo, Ácies e círculo bíblico...

Vel: Agora é a chamada... Irene ajude aí irmã Lourdes a fazer a chamada...

Depois da descrição dos dados encontrados, passamos às reflexões sobre o que poderia explicar a diversidade de formas de tratamento e, em especial, a diferença de tratamento atribuída ao único membro do sexo masculino. Segundo o modelo de Brown e Gilman (2003 [1960]), formas de tratamento sinalizam relações de poder instauradas, em relações assimétricas e simétricas, sempre em função do falante. As línguas possuem, de maneira geral, formas de relação superior - inferior, genericamente formas T, e formas de relação inferior - superior, genericamente formas V. A comunidade de prática analisada é marcada por relações assimétricas, já que se constitui por líderes - membros oficiais - e liderados. No entanto, não é a relação líder/liderado que determina a escolha das formas de tratamento: os fatores que parecem influenciar a forma de tratamento são relacionados à faixa etária (mais velhos, maior poder na estrutura social da comunidade), e também de gênero, na medida que há um único homem no grupo, que é, também, um dos membros mais velhos que compõe a comunidade. A cumulação dos fatores - homem e mais velho - faz com que Edv se dirija às demais membros da comunidade diretamente pelo nome, inclusive às que ocupam função de oficiais, e receba sempre o tratamento de deferência, com "seu" e "senhor". 


\section{CONSIDERAÇÕES FINAIS}

A análise qualitativa das formas de tratamento em uma comunidade de práticas religiosas permitiu desvelar como se constitui linguisticamente um sistema de valores arraigado na comunidade, qual seja, o poder concentrado na figura do membro masculino e mais velho.

A despeito da hierarquia inerente ao grupo, com a categorização de membros oficiais e membros participantes, o critério para a sinalização de deferência linguística é outro, relacionado aos papéis de gênero e de faixa etária. A comunidade sob análise reúne traços conservadores (por ser de cunho religioso, em uma localidade do interior), que são reforçados com a assimetria de gênero identificada pelo uso das formas de tratamento.

\section{REFERÊNCIAS}

BROWN, R.; GILMAN, A. The pronouns and solidarity. In: PAULSTON, C. B \& TUCKER, G. R. (eds.). Sociolinguistics: The Essential Readings. Oxford: Blackwell, pp. 156-163. [original de 1960]

ECKERT, Penelope. Three waves of variation study: the emergence of meaning in the study of sociolinguistic variation. Annual Review of Anthropology, n. 41, p. 87-100, 2012.

ECKERT; P; MCCONNELL-GINET, S. Comunidades de práticas: lugar onde co-habitam linguagem, gênero e poder. In: OSTERMANN, A. C.; FONTANA, B. Linguagem, sexo, sexualidade. São Paulo: Parábola Editorial, 2010. [original de 1992]

FREITAG, Raquel Meister Ko. Banco de dados falares sergipanos. Working Papers em Linguística, v. 14, n. 2, p. 156-164, 2013.

FREITAG, Raquel Meister Ko. Covariação em uma comunidade de práticas. In: Norma da Silva Lopes; Jânia Ramos; Josane Moreira de Oliveira. (Org.). Diferentes olhares sobre o português brasileiro. Feira de Santana: Editora UEFS, 2014, p. 13-30.

FREITAG, Raquel Meister Ko.; MARTINS, Marco Antonio; TAVARES, Maria Alice. Bancos de dados sociolinguísticos do português brasileiro e os estudos de terceira onda: potencialidades e limitações. Alfa: Revista de Linguística, v. 56, p. 917-944, 2012.

FREITAG, Raquel Meister Ko.; SANTANA, Cristiane Conceição; ANDRADE, Thaís Regina Conceição. Práticas constitutivas do povoado Açuzinho. Ambivalências, v. 2, n. 03, p. 194-217, 2014. 